\title{
Urban and Rural Disparities in Healthcare Utilization and Expenditures Among Rural Hukou Beneficiaries of New Cooperative Medical Scheme in China
}

Dian Luo

Emory University https://orcid.org/0000-0003-2907-4831

Yingjie Ma

Chongqing University

Jing Deng ( $\nabla$ cqmudj@126.com )

https://orcid.org/0000-0001-6032-6529

Research article

Keywords: Healthcare utilization, Healthcare expenditure, New Cooperative Medical Scheme, China, CHARLS 2015

Posted Date: October 11th, 2019

DOI: https://doi.org/10.21203/rs.2.15908/v1

License: (c) (i) This work is licensed under a Creative Commons Attribution 4.0 International License. Read Full License 


\section{Abstract}

\section{Background}

The New Cooperative Medical Scheme (NCMS) is a social health insurance available to rural Chinese residents. Over time, several concerns to this system have been raised, including disparities among healthcare utilization and expenditures. Most studies only discuss disparities in general in NCMS, with few studies concentrating on comparing disparities between urban and rural regions. Moreover, this issue has an increasing importance due to the rapid population growth of rural migrants. Therefore, we conducted our study to explore urban and rural disparities among NCMS beneficiaries.

\section{Methods}

Our study is based on Chinese Health and Retirement Longitudinal Study (CHARLS) for 2015. Our targeted sample is individuals with rural hukou and only covered by NCMS. We define and use influential factors in our logistic regressions and descriptive tables to compare urban and rural disparities among these NCMS beneficiaries.

\section{Results}

In terms of inpatient care, urban beneficiaries have a lower probability $(\mathrm{OR}=1.013, \mathrm{P}=0.892)$ and frequency (1.39 vs. $1.47, \mathrm{P}=0.131$ ) of having an inpatient visit than rural beneficiaries. However, urban beneficiaries have higher out-of-pocket (OOP) expenditures among inpatient visit ( $₫ 6788.98$ vs. $\$ 6163.92$,

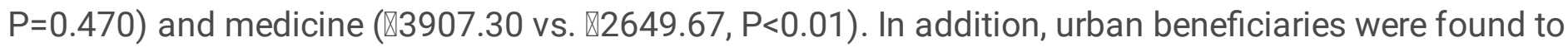

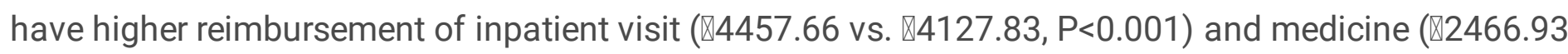
vs. $\otimes 1774.55, P<0.05)$. In terms of outpatient care, urban beneficiaries have less possibility $(O R=1.074$, $P=0.384)$ and frequency ( 2.15 vs. $2.26, P=0.225)$ of an outpatient visit than rural beneficiaries. Moreover, compared to rural beneficiaries, urban beneficiaries have less out-of-pocket (OOP) expenditures of outpatient visit ( $\nabla 709.80$ vs. $\nabla 710.98, P=0.608)$ and drugs ( $\nabla 448.68$ vs. $\nabla 522.95, P=0.645)$, and less reimbursement of outpatient visit ( $\nabla 296.03$ vs. $\otimes 344.51, P=0.808)$ and drugs ( $\nabla 99.25$ vs. $\otimes 114.60$, $\mathrm{P}<0.05)$.

\section{Conclusion}

In terms of healthcare utilization, rural beneficiaries have both higher probability and frequency of inpatient and outpatient visits. In terms of healthcare expenditures, urban beneficiaries get more inpatient reimbursement with higher inpatient expenditures, while rural beneficiaries get more outpatient reimbursement with higher outpatient expenditures. Both situations have not solid answer yet, and therefore require further research.

\section{Introduction}


New Cooperative Medical Scheme (NCMS) has raised a lot of concerns, and disparity in healthcare utilization and expenditures is one of them[1][2][3][4]. These disparities indicate benefits of NCMS are concentrated toward economically affluent or scarce groups instead of distributing equally. New Cooperative Medical Scheme (NCMS) was established in 2003 to provide financial protection for rural residents. It is a voluntary program based on cost sharing between government and rural residents, which covers mostly inpatient services and a few outpatient services[5]. It is designed to enable beneficiaries to enjoy same the same benefits package by paying a flat-rate premium. Therefore, beneficiaries are likely to get more reimbursement with more healthcare utilization and expenditures. Moreover, economical affluent groups are more likely to consume more medical services, which usually get more reimbursement [6][7][8]. Since NCMS is Social Medical Insurance (SMI) and originally designed to be a financing approach for mobilizing funds and pooling risk, these mobilized funds should be allocated for the poor and near-poor rural residents rather than economically affluent groups[9]. When NCMS was firstly established in 2003, rural residents generally lived in rural area with similar economic profiles. In this setting, disparities in healthcare utilization and expenditures were not a serious concern among these NCMS beneficiaries.

However, with economic boom and rapid urbanization, an increasing number of rural residents migrate from rural to urban areas seeking better employment opportunities. This rural migrates grown rapidly that reached 277.5 million of Chinese population by the end of 2015[10]. Therefore, rural migrants play a significant role in Chinese current SMI due to its large population. However, compared to original urban residents, these rural migrants have limited access to a range of social services due to the Chinese unique household registration system (hukou system), which includes healthcare services[11]. In general, individuals born in rural areas are assigned to a rural hukou status, and individuals born in urban areas are assigned to urban hukou. Moreover, such a hukou status is hard to be modified even when individuals move from rural to urban areas[12]. Therefore, there is a considerable number of rural migrants who live in urban areas with rural hukou status, who are covered by NCMS, and who are economical affluent groups.

At first glimpse of our analysis before, rural migrants have the potential to cause disparities in healthcare utilization and expenditures due to their affluent economic profile compared to rural residents. Better economic profile enables them to use more healthcare services and thus get more reimbursement. As a result, this unequally distribution of benefits makes an inefficient use of risk pooling and thus deviates the original goal of NCMS[13]. However, rural migrants are also constrained by many barriers when we have a close look. These barriers include lack of knowledge of NCMS, difficult reimbursement policies, and lack of health awareness[14][15][16][17]. Accordingly, an uncertainty of the direction of disparity distribution among NCMS beneficiaries was raised. Furthermore, there are limited studies discussing disparities in healthcare utilization and expenditures between urban and rural. The purpose of this study is to explore disparities between urban and rural communities based on healthcare utilization and expenditures. In our study, we defined urban beneficiaries as NCMS beneficiaries living in urban area with rural hukou and rural beneficiaries as NCMS beneficiaries living in rural area with rural hukou. We define 
pro-rural inequity as benefits concentrating toward rural beneficiaries, and pro-urban inequity as benefits concentrating toward urban beneficiaries.

\section{Methods}

\section{Database}

This study used Chinese and Health and Longitudinal Retirement Survey (CHARLS) 2015. This is a nationally representative survey that examines the social, financial, and health circumstances of citizens in mainland China. The main questionnaire includes information on basic demographic backgrounds, family structure and financial support, health status and functioning, healthcare and insurance, work, retirement and pension, income, expenditures and assets, and housing characteristics. Based on a probability proportionate to size sampling strategy, CHARLS covers 450 communities in 150 counties from 28 of the 32 provinces in mainland China. Households are randomly selected from maps and listings within each rural or urban community. Residents aged 45 years or older and their spouses (if any, and of any age) were interviewed at baseline and after a 2-year period.

The dataset was established through four steps. First, county-level units (counties or urban districts) were sampled directly. These scope of counties covers 28 of 30 provinces in mainland China, excluding Tibet. Second, based on recently updated village-level population data, the National Bureau of Statistics assisted to selected village and community units within county units. Primary sampling units (PSUs) were created on the basis of administrative villages in rural areas and neighborhoods in urban areas. 450 PSUs of the total PSUs were then selected by probability proportional to size (PPS) sampling methods, and three PSUs were selected in each county-level unit. Third, household units were selected in each PSU. The sampling structure was constructed by Google Earth base maps. A computer-assisted personal interview program was used to sample households. Portable computers were used to conduct the interviews. Specifically, GPS information was collected by photographing the door of each household. Fourth, all of the respondents were required to fill out each module of the questionnaire through the personal interview program in the portable computer. The data was then uploaded to the project group at the end of each day. Finally, all age-eligible sample households who were willing to participate in the survey were interviewed[18].

\section{Sample}

In our study, 21,097 individuals from 12,235 households participated in CHARLS 2015. 14,524 participants who were confirmed to be covered by NCMS were selected. Since 1,064 participants were not covered by other health insurance as well as NCMS, 13,478 participants covered by NCMS uniquely were included in the analysis. Participants with urban hukou or with missing values in hukou status were dropped, with 12,251 participants remaining. Among these participants, 3,062 participants lived in urban area and 9,189 participants lived in rural area (figure 1). 


\section{Variables}

\section{Dependent variables}

In our study, we examined two outcomes: 1): whether beneficiaries had an inpatient visit last year; 2): whether beneficiaries had an outpatient visit last month;

\section{Independent variables}

According to the Anderson Health Services Utilization Initial Model[19], the following elements are associated with the utilization of health care services: 1) propensity characteristics: gender, age, household living area, marital status and educational level; 2) capacity resources: total household annually expenditure per capita (PCE), and work status; 3 ) health needs: self-report health status, chronic disease condition, and BMI. Of note, One thing needs to be emphasized is that we used total annually household consumption per capita not total annually household income per capita to measure living standard[20]. Since the majority of our sample is rural hukou elderly, a large number of them do not work due to retirement. Therefore, the total household consumption is a better method to measure their wealth condition. Moreover, nearly $30 \%$ of our sample are under agricultural work and their income varies in different seasons. All the variables above are defined in Additional file 1.

\section{Other measures}

Since we want to compare the difference in healthcare utilization and expenditures between two subgroups, there are other variables not included in our model but only used to conduct a descriptive statistical analysis. Additional file 2 displays the definition of variables we used to compare the differences in healthcare utilization and expenditures between rural migrants and rural residents. In terms of healthcare utilization, we use hospital type and conditional times of healthcare visit (beneficiaries who have at least one healthcare visit) to compare differences between two subgroups. In terms of healthcare expenditures, we use total expenditure, out-of-pocket expenditure and reimbursement of healthcare visit and medicine to compare differences between the two subgroups. Specifically, healthcare visit expenditures and medicine expenditures are considered separately. Healthcare visit expenditures only include fees for the physician or hospital services without medication. Moreover, we also used reimbursement rate to measure expenditure proportions. This allowed us to better explain an individual's healthcare costs as a proportion of their total expenditure, rather than using absolute values.

\section{Statistical analysis}


We examined both outcomes: 1): whether beneficiaries had an inpatient visit last year; 2): whether beneficiaries had an outpatient visit last month. Using the entire sample $(N=13,478)$, regardless of whether there was a healthcare visit. The following covariates were adjusted in the analysis to explore which demographic characteristics were associated to these outcomes: age, total household annually consumption per capita, gender, educational level, marital status, hukou status, self-report, work status, chronic disease type and BMI. Total household annually expenditure per capita (PCE) were transformed into a normal distribution by using the natural logarithm. Finally, we used logistic regression to test the association between our outcomes and sociodemographic characteristics. For descriptive analysis, categorical variables are analyzed by Fisher exact test, and continuous variables are analyzed by Wilcoxon rank sum test. Our significant level is set at 0.05 , and all of our analyses are conducted with StataSE 15 (StataCorp, College Station, USA).

\section{Results}

\section{Demographic characteristics}

Table 1 displays the results of demographic characteristics. In general, all of the demographic characteristics are significantly associated with living area. Compared to rural beneficiaries, urban beneficiaries are younger with higher educational level, higher self-reported health status, less unemployment percentage, and lower BMI.

Specifically, urban beneficiaries have significantly higher total annual household consumption per capita

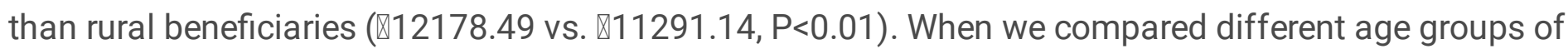
the two subgroups, we found urban beneficiaries are less concentrated in higher age groups compared to rural beneficiaries $(P<0.01) .29 .06 \%$ of urban beneficiaries are over 65 years old, compared to that of rural beneficiaries, $32.79 \%$. $32.56 \%$ of urban beneficiaries are between 45 years old and 54 years old, compared to that of rural beneficiaries, $30.21 \%$. The proportion of gender between the two subgroups is interesting. Urban beneficiaries have a higher proportion of females compared to rural beneficiaries $(55.81 \%$ vs. $52.93 \%, P<0.01)$. As for educational level, urban beneficiaries have a clear higher education level than rural beneficiaries $(P<0.01) .23 .39 \%$ of urban beneficiaries don't have any formal education, which is considerably more than that of rural beneficiaries $(31.74 \%)$. For marital status, these trends are similar. As for work status, urban beneficiaries are less likely to have agricultural work compared to rural beneficiaries $(55.42 \%$ vs. $35.66 \%, P<0.01)$. Urban beneficiaries are also less likely to be unemployed than rural beneficiaries $(23.17 \%$ vs. $30.94 \%, P<0.01)$.

As for self-report health status, urban beneficiaries are slightly in better health compared to rural beneficiaries (good: $17.13 \%$ vs. $15.81 \%$; fair: $56.23 \%$ vs. $51.85 \%$; poor: $26.64 \%$ vs. $32.34 \%, P<0.01$ ). The overall prevalence of chronic disease is $69.86 \% .69 .0 \%$ of urban beneficiaries have chronic diseases, while $70.15 \%$ of rural beneficiaries have chronic diseases. The prevalence of chronic diseases is severe in both two subgroups. When chronic diseases are strata defined by different specific chronic diseases, the proportion between the two subgroups is also similar. In particular, hypertension and diabetes are the 
most prevalent and severe diseases among both subgroups, and over $40 \%$ of participants with these two chronic diseases. As for BMI, nearly $50 \%$ of the total sample size are identified as overweight or obese. Compared to rural beneficiaries, urban beneficiaries have slightly higher proportion in both overweight ( $26.16 \%$ vs. $22.28 \%)$ and obesity groups $(26.23 \%$ vs. $22.05 \%)$, as well as a lower proportion in healthy group $(43.36 \%$ vs. $50.08 \%)$.

\section{Healthcare service utilization and expenditures}

\section{Inpatient care last year}

Table 2 displays healthcare utilization and expenditures of inpatient care. In general, urban beneficiaries have slightly fewer inpatient visits ( 1.39 vs. $1.47, \mathrm{P}=0.131)$ than rural beneficiaries. Of note, most individuals in both subgroups have an inpatient care at the hospitals which are not basic health facilities (urban beneficiaries: $82.84 \%$ vs. $17.16 \%$; rural beneficiaries: $76.9 \%$ vs. $23.1 \%, P=0.022$ ).

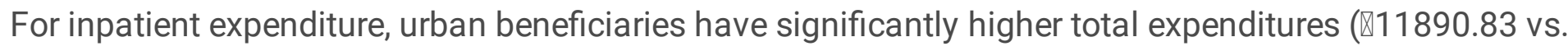

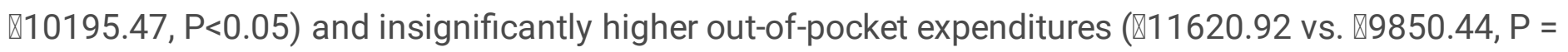
$0.175)$ with significantly higher reimbursement $(\varangle 4457.66$ vs. $₫ 4127.83, P<0.001)$ compared to rural beneficiaries. Of note, urban beneficiaries have significant higher total drug expenditures ( $₫ 6087.47 \mathrm{vs}$. $\llbracket 4170.30, P<0.01)$ and out-of-pocket drug expenditures ( $₫ 3907.30$ vs. $₫ 2649.67, P<0.01)$ with significantly higher drug reimbursement ( $₫ 2466.93$ vs. $₫ 1774.552, P<0.05)$.

Urban beneficiaries have significantly higher inpatient visit reimbursement rate $(41.7 \%$ vs. $37.5 \%, P<0.05)$, but similar inpatient drug reimbursement rate $(33.6 \%$ vs. $32.1 \%, P=0.452)$.

\section{Outpatient care last month}

Table 3 displays healthcare utilization and expenditures of inpatient care. Urban beneficiaries have slightly fewer outpatient visits than rural beneficiaries ( 2.15 vs. $2.26, P=0.375)$ among individuals who have at least one outpatient visit. Both subgroups select to have an outpatient care mainly in basic facilities (urban beneficiaries: $29.69 \%$ vs. $70.31 \%$; rural beneficiaries: $27.15 \%$ vs. $72.85 \%, P=0.247$ ), which is inversely to that of inpatient care.

In terms of outpatient care, urban beneficiaries have considerably higher total outpatient expenditures ( $₫ 997.79$ vs. $\nabla 904.21, P=0.897$ ) and similar outpatient out-of-pocket expenditures ( $\nabla 709.80$ vs. $\nabla 710.98, P$ $=0.608$ ) with lower outpatient reimbursement ( $₫ 296.03$ vs. $₫ 344.51, P=0.808)$. In terms of drug expenditure, urban beneficiaries spend significantly less on drugs. Urban beneficiaries have clearly fewer expenditures in total drug expenditures ( $\nabla 468.67$ vs. $₫ 575.47, \mathrm{P}=0.464$ ) and drug out-of-pocket 
expenditures ( $₫ 448.68$ vs. $₫ 522.95, P=0.645)$ with slightly lower reimbursement $(\nabla 99.25$ vs. $\nabla 114.60, P=$ $0.594)$.

Urban beneficiaries have similar healthcare visit reimbursement rates $(13.8 \%$ vs. $13.1 \%, P=0.677)$ and drug reimbursement rates $(9.2 \%$ vs. $10.0 \%, P=527)$.

\section{Regression results}

The logistic regression results are generally consistent with our descriptive tables, which are showed in table 4 and table 5. For inpatient care, living in a rural area is associated with having inpatient patient care $(O R=1.013, P=0.892)$. Self-report status is highly related to inpatient care especially for poor status $(\mathrm{OR}=4.81, \mathrm{P}<0.001)$. Compared to beneficiaries who are unemployed, beneficiaries either have agricultural work $(\mathrm{OR}=0.689, \mathrm{P}<0.001)$ or a non-agricultural work $(\mathrm{OR}=0.607, \mathrm{P}<0.001)$ are less likely to have an inpatient care. Moreover, compared to beneficiaries who do not have chronic diseases, chronic diseases are significantly associated with inpatient visit $(P<0.001)$. In particular, beneficiaries who have both diabetes and hypertensions have the highest possibility of having inpatient care $(O R=2.480$, $P<0.001)$. $P C E$ is also significantly related to having an inpatient care $(O R=1.495, P<0.001)$.

For outpatient care, living in a rural area is associated with having an outpatient care $(\mathrm{OR}=1.074, \mathrm{P}=$ 0.380). However, work status is not significantly related to outpatient care as it is inpatient care. Selfreported status is still significantly related to outpatient care. Poor health status has the highest probability to have an outpatient care $(\mathrm{OR}=4.811, \mathrm{P}<0.001)$. Moreover, beneficiaries who have diabetes have the highest possibility to have an outpatient care $(O R=1.699, P<0.001)$. $P C E$ is not highly related to having outpatient care $(\mathrm{OR}=1.071, \mathrm{P}=0.081)$.

\section{Discussion}

The purpose of this study was to characterize the distribution of healthcare utilization and expenditures among NCMS beneficiaries. We found that rural beneficiaries have both higher probability and frequency of healthcare visit in terms of both inpatient care and outpatient care than urban beneficiaries. Rural beneficiaries have higher outpatient OOP expenditures and therefore get more outpatient reimbursement rate. Urban beneficiaries have higher inpatient OOP expenditures and therefore get more inpatient reimbursement rate. Of note, drug expenditures and severe chronic diseases are need more attention.

\section{Demographic characteristics}

All our demographic characteristics are significant associated with living area. There are no surprising findings as all these results are consistent with empirical experiences. Urban beneficiaries are younger and wealthier with better self-reported health status as well as higher educational level. A surprising finding was the high prevalence of chronic disease in both subgroups, and half of both subgroups are 
either overweight or obese. Moreover, our regression results show chronic diseases are significantly related to healthcare visits. Therefore, chronic disease is a key factor contributing to medical expenditures, which is consistent with other studies[21][22].

\section{Healthcare utilization and expenditures}

From this analysis, we have a better understanding of healthcare utilization and expenditures in China. Urban beneficiaries have slightly less probability and frequency to have both inpatient care and outpatient care than rural beneficiaries. Moreover, urban beneficiaries have higher expenditures and reimbursement in inpatient visit and drug, while outpatient care has an inverse situation. Therefore, in terms of healthcare utilization, there is a pro-rural inequity on both inpatient and outpatient visits. In terms of healthcare expenditures, there is a pro-urban inequity on inpatient expenditures, whereas while a prorural inequity on outpatient expenditures.

While we do not know the underlying reason for the truth of why urban beneficiaries have less probability and frequency of healthcare visit, we have found several factors to be associated. One suggestion is that urban beneficiaries are healthier, so they will need fewer healthcare visits. However, such a difference in health condition between rural and urban beneficiaries is not supported by our data. Based on this situation, we have come up with other two reasons to explain it. The first reason is unacceptable destination bill policy of NCMS. It means when NCMS beneficiaries have a medical bill, they have come back to their original registration places to get full reimbursement. If not, they can only get part of the reimbursement or none of the reimbursement. Returning to these original registration places is timeconsuming and expensive in terms of transportation costs. This kind of behavior is called medical return. Therefore, a beneficiary may select to get only partly reimbursed, while another beneficiary may decide to reduce their healthcare visits or not seek healthcare treatment. In our data, we do not find that urban beneficiaries have a lower reimbursement rate than rural beneficiaries. This suggests urban beneficiaries choose to reduce their healthcare utilization. The second reason is effectiveness of treatment methods. This explanation means that urban beneficiaries are more likely to use more effective treatment methods that may have higher expenditures but would reduce the likelihood of repeat treatment/healthcare costs. This inference is consistent with our data that urban beneficiaries have less healthcare visits but more total healthcare expenditures.

In terms of inpatient care, there is a pro-rich inequity. We can find urban beneficiaries have significantly higher reimbursement amounts and rates than rural beneficiaries in inpatient care, particularly those beneficiaries receiving drugs. This can also be partly explained by the effectiveness of treatment methods. Urban beneficiaries use more effective methods, so they spend more. However, the differences on inpatient drug expenditures are relatively high between the two subgroups, which needs more attention. Some studies point that doctors usually receive some revenues they generate within the hospitals. Therefore, they are incentivized to prescribe more drugs, especially for the insured ones with better ability to pay[23][24]. Moreover, some studies also suggest most drugs sold in hospital pharmacies 
are charged at a higher profit margin than the wholesale price, and pharmaceutical companies may even offer doctors kickbacks from selling their drugs[25].

In terms of outpatient care, we find an inverse situation that urban beneficiaries spend less and get less reimbursement, so there is a pro-poor inequity. In our opinion, this phenomenon can be partly explained price elasticity[7]. Compared to inpatient care, the price of outpatient care is more reasonable to most beneficiaries, so they will seek outpatient care instead of inpatient care as far as possible. These results can also be justified by our regression results that PCE is significantly associated with inpatient care while insignificantly associated with outpatient care. However, as we mentioned previously, rural beneficiaries have less PCE while they spend more than urban beneficiaries, so they will face a higher economic burden than urban beneficiaries. This problem will be aggravated by lower outpatient reimbursement compared to inpatient care, because NCMS is designed to mainly cover inpatient care.

\section{Policy recommendation}

Based on our analysis, disparities in healthcare utilization and expenditures are varied between rural and urban beneficiaries of NCMS in China. In terms of inpatient care, the government is supposed to reduce pro-urban inequity in healthcare expenditures, particularly on drugs. In terms of outpatient care, although there is a pro-rural inequity in healthcare expenditures, the problem is less important compared to low reimbursement. Therefore, the government is supposed to increase outpatient reimbursement to provide more financial protection to rural residents.

Currently, the Chinese government is combining Urban and Rural Medical Scheme (URMS) and NCMS to form a new health insurance, which is based on an income-match financing method. This combination will reduce some barriers for rural migrants to access healthcare services due to hukou status, and higher reimbursement rate in both inpatient and outpatient visit will also reduce economic burden of rural hukou individuals. From this perspective, our findings can be a proof of concept to support the combination of URMS and NCMS[3][26][27]. However, this kind of reform also need some adjustments. The first adjustment is supposed to reform the drug delivery system as well as the payment system to control costs and reduce the potentially for drug prescription abuse. Based on our analysis, a new payment system is necessary to be introduced. Two examples of prospective payment methods that could be suitable for China include the Diagnosis Related Group (DRG) payment method for hospitals and riskadjusted capitation payment method for primary-care providers. Both of these payment methods reimburse providers by a fixed amount depending on certain characteristics of their patients-the disease profile under DRG, and demographic characteristics under capitation payment method. Physicians thus have an incentive to keep costs down to avoid exceeding the fixed reimbursement amount. These two payment methods have been successful in many other countries, which mat be helpful to the Chinese government[28][29].

\section{Conclusions}


Our study finds there are some urban and rural disparities in healthcare utilization and expenditures of NCMS beneficiaries. In terms of healthcare utilization, rural migrants have lower probability and frequency in both inpatient care and outpatient care, so there is a pro-rural inequity in both inpatient and outpatient care. In terms of healthcare expenditures, these disparities generally show a pro-urban inequity in inpatient expenditures and pro-poor inequity in outpatient expenditures. The pro-rural inequity in healthcare utilization is a surprising finding and requires further research. Moreover, we recommend the further reform of NCMS in order to reduce urban and rural disparities, including new drug system and payment system to control medical costs.

\section{Limitations}

Our study also has some limitations. We did not consider provinces due to limited sample size. Since NCMS is jointly subsidized by central and local government, it is an important factor to consider in the future studies[30]. Since we cannot identify the healthcare quality of healthcare visit, we cannot evaluate whether rural migrants receive better healthcare services with higher healthcare expenditures. We cannot identify the location where urban beneficiaries have inpatient care and outpatient care, and thus we cannot identify whether medical return behavior happens. Admittedly, moral hazard and adverse selection are also two potential factors that will weaken our conclusion. In particular, for adverse selection, it is a critical problem of voluntary group insurance[9]. The present study uses a cross-sectional data for analysis, which prevents us from discussing its findings based on causal relationships. For instance, we cannot infer that high medical expenditure of urban residents is caused by their selections or persuasion from hospitals. In addition, all the information about health care utilization and living standard was selfreported, which may have led to a reporting bias. Finally, CHARLS is mainly constituted by people over 45 , so our results may not be consistent with young people less than 45 years of age.

\section{Abbreviations}

CHARLS: China Health and Retirement Longitudinal Study

\section{Declarations}

Ethics approval and consent to participate

The current study is a secondary analysis of the de-identified China Health and Retirement Longitudinal Study (CHARLS) public data. The original CHARLS was approved by the Ethical Review Committee of Peking University, and all participants signed the informed consent at the time of participation.

Consent to publish

Not applicable.

Availability of data and materials 
The datasets analyzed during the current study are publicly available in the CHARLS repository at http://charls.pku.edu.cn/en

Competing interests

The authors declare that they have no competing interests.

Funding

This study was not funded by external grant sources.

Authors' contributions

Both authors participated in the study design, statistical analysis, and manuscript preparation.

Acknowledgment

This analysis uses data or information from the Harmonized CHARLS dataset and Codebook, Version B.4 as of February 2017 developed by the Gateway to Global Aging Data.

\section{Reference}

[1]X. Fu et al., "Influencing factors of inequity in health services utilization among the elderly in China," Int. J. Equity Health, vol. 17, no. 1, p. 144, 2018.

[2]C. Li, L. Dou, H. Wang, S. Jing, and A. Yin, "Horizontal Inequity in Health Care Utilization among the Middle-Aged and Elderly in China," International Journal of Environmental Research and Public Health, vol. 14, no. 8. 2017.

[3]S. Lai et al., "The distribution of benefits under China's new rural cooperative medical system: evidence from western rural China," Int. J. Equity Health, vol. 17, no. 1, p. 137, 2018.

[4]Z. Wang, Y. Chen, T. Pan, X. Liu, and H. Hu, "The comparison of healthcare utilization inequity between URRBMI and NCMS in rural China.," Int. J. Equity Health, vol. 18, no. 1, p. 90, Jun. 2019.

[5]W. Yip and W. C. Hsiao, "Non-evidence-based policy: How effective is China's new cooperative medical scheme in reducing medical impoverishment?," Soc. Sci. Med., vol. 68, no. 2, pp. 201-209, 2009.

[6]D. Blumenthal and W. Hsiao, "Lessons from the East-China's rapidly evolving health care system.," $N$. Engl. J. Med., vol. 372, no. 14, pp. 1281-1285, Apr. 2015.

[7]M. Yang, "Demand for social health insurance: Evidence from the Chinese New Rural Cooperative Medical Scheme," China Econ. Rev., vol. 52, pp. 126-135, 2018. 
[8]B. Xie et al., "Impact of the New Cooperative Medical Scheme on the trend of catastrophic health expenditure in Chinese rural households: results from nationally representative surveys from 2003 to 2013," BMJ Open, vol. 8, no. 2, p. e019442, Feb. 2018.

[9]W. C. Hsiao and R. P. Shaw, Social Health Insurance for Developing Nations. The World Bank, 2007.

[10]W. Chen, Q. Zhang, A.M. N. Renzaho, F. Zhou, H. Zhang, and L. Ling, "Social health insurance coverage and financial protection among rural-to-urban internal migrants in China: evidence from a nationally representative cross-sectional study.," BMJ Glob. Heal., vol. 2, no. 4, p. e000477, 2017.

[11]L. Kuang and L. Liu, "Discrimination against rural-to-urban migrants: the role of the hukou system in China," PLoS One, vol. 7, no. 11, pp. e46932-e46932, 2012.

[12]C. Chen and C. C. Fan, "China's Hukou Puzzle: Why Don't Rural Migrants Want Urban Hukou?," China Rev., vol. 16, no. 3, pp. 9-39, 2016.

[13]P. Qiu, Y. Yang, J. Zhang, and X. Ma, "Rural-to-urban migration and its implication for new cooperative medical scheme coverage and utilization in China.," BMC Public Health, vol. 11, p. 520, Jun. 2011.

[14]C. Li and L. H. Lumey, "Impact of disease screening on awareness and management of hypertension and diabetes between 2011 and 2015: results from the China health and retirement longitudinal study.," BMC Public Health, vol. 19, no. 1, p. 421, Apr. 2019.

[15]B. Peng and L. Ling, "Association between rural-to-urban migrants' social medical insurance, social integration and their medical return in China: a nationally representative cross-sectional data analysis," BMC Public Health, vol. 19, no. 1, p. 86, 2019.

[16]I. Nielsen, C. Nyland, R. Smyth, M. Zhang, and C. J. Zhu, "Which Rural Migrants Receive Social Insurance in Chinese Cities?: Evidence from Jiangsu Survey Data," Glob. Soc. Policy, vol. 5, no. 3, pp. 353-381, Dec. 2005.

[17]Y. Peng, W. Chang, H. Zhou, H. Hu, and W. Liang, "Factors associated with health-seeking behavior among migrant workers in Beijing, China.," BMC Health Serv. Res., vol. 10, p. 69, Mar. 2010.

[18]Y. Zhao, Y. Hu, J. P. Smith, J. Strauss, and G. Yang, "Cohort profile: the China Health and Retirement Longitudinal Study (CHARLS).," Int. J. Epidemiol., vol. 43, no. 1, pp. 61-68, Feb. 2014.

[19]R. M. Andersen, "Revisiting the behavioral model and access to medical care: does it matter?," J. Health Soc. Behav., vol. 36, no. 1, pp. 1-10, Mar. 1995.

[20]Z. Zhou et al., "Measuring the equity of inpatient utilization in Chinese rural areas," BMC Health Serv. Res., vol. 11, no. 1, p. 201, 2011. 
[21]Y. Xu et al., "Catastrophic health expenditure in households with chronic disease patients: A pre-post comparison of the New Health Care Reform in Shaanxi Province, China," PLoS One, vol. 13, no. 3, p. e0194539, Mar. 2018.

[22]T. Zhai, J. Goss, and J. Li, "Main drivers of health expenditure growth in China: a decomposition analysis," BMC Health Serv. Res., vol. 17, no. 1, p. 185, 2017.

[23]F. Lu, "Insurance coverage and agency problems in doctor prescriptions: Evidence from a field experiment in China," J. Dev. Econ., vol. 106, pp. 156-167, 2014.

[24]W. Yip and W. Hsiao, "China's health care reform: A tentative assessment," China Econ. Rev., vol. 20, no. 4, pp. 613-619, 2009.

[25]H. Yi, G. Miller, L. Zhang, S. Li, and S. Rozelle, "Intended And Unintended Consequences Of China's Zero Markup Drug Policy," Health Aff., vol. 34, no. 8, pp. 1391-1398, Aug. 2015.

[26]D. Su et al., "Effect of integrated urban and rural residents medical insurance on the utilisation of medical services by residents in China: a propensity score matching with difference-in-differences regression approach," BMJ Open, vol. 9, no. 2, pp. e026408-e026408, Feb. 2019.

[27]Q. Meng, H. Fang, X. Liu, B. Yuan, and J. Xu, "Consolidating the social health insurance schemes in China: towards an equitable and efficient health system.," Lancet (London, England), vol. 386, no. 10002, pp. 1484-1492, Oct. 2015.

[28]M. Nejati, M. Razavi, I. Harirchi, K. Zendehdel, and P. Nejati, "The impact of provider payment reforms and associated care delivery models on cost and quality in cancer care: A systematic literature review," PLoS One, vol. 14, no. 4, p. e0214382, Apr. 2019.

[29]S. Y. Tan, G. J. Melendez-Torres, and T. Pang, "Implementation of provider payment system reforms in the age of universal health coverage: a realist review of evidence from Asian developing countries.," J. Health Serv. Res. Policy, p. 1355819619842305, Apr. 2019.

[30]H. H. Dib, X. Pan, and H. Zhang, "Evaluation of the new rural cooperative medical system in China: is it working or not?," Int. J. Equity Health, vol. 7, no. 1, p. 17, 2008.

\section{Tables}

Table 1: Demographic statistics of individuals with rural hukou status covered by NCMS 


\begin{tabular}{|c|c|c|c|c|c|c|c|}
\hline & NCMI & & & & & & \\
\hline & Total & & Urban & & Rural & & \\
\hline & Mean & SD & Mean & SD & Mean & SD & $\mathrm{P}$ \\
\hline \multirow[t]{3}{*}{ PCE } & 11507.44 & 130.68 & 12178.49 & 275.38 & 11291.14 & 148.18 & 0.000 \\
\hline & Total & & Urban & & Rural & & \\
\hline & Count & $\%$ & Count & $\%$ & Count & $\%$ & \\
\hline Overall & 12,251 & 100.00 & 3,062 & 24.99 & 9,189 & 75.01 & \\
\hline \multicolumn{8}{|l|}{ Age } \\
\hline $45-$ & 716 & 5.85 & 187 & 6.12 & 529 & 5.76 & 0.001 \\
\hline $45-54$ & 3,770 & 30.8 & 995 & 32.56 & 2,775 & 30.21 & \\
\hline $55-64$ & 3,855 & 31.49 & 986 & 32.26 & 2,869 & 31.24 & \\
\hline $65+$ & 3,900 & 31.86 & 888 & 29.06 & 3,012 & 32.79 & \\
\hline \multicolumn{8}{|l|}{ Gender } \\
\hline Male & 5,678 & 46.35 & 1,353 & 44.19 & 4,325 & 47.07 & 0.006 \\
\hline Female & 6,573 & 53.65 & 1,709 & 55.81 & 4,864 & 52.93 & \\
\hline \multicolumn{8}{|l|}{ Educational level } \\
\hline No formal education & 3,627 & 29.65 & 715 & 23.39 & $\overline{2,912}$ & 31.74 & 0.000 \\
\hline$<=$ Elementary school & 5,874 & 48.03 & 1,591 & 52.04 & 4,283 & 46.69 & \\
\hline$>=$ Middle school & 2,730 & 22.32 & 751 & 24.57 & 1,979 & 21.57 & \\
\hline \multicolumn{8}{|l|}{ Marital status } \\
\hline Living with spouse & 9,823 & 80.18 & 2,498 & 81.58 & 7,325 & $\overline{79.71}$ & 0.026 \\
\hline Living without spouse & 2,428 & 19.82 & 564 & 18.42 & 1,864 & 20.29 & \\
\hline \multicolumn{8}{|l|}{ Work status } \\
\hline No employment & 3,040 & 25.1 & 931 & 30.94 & 2,109 & 23.17 & 0.000 \\
\hline Agricultural work & 6,117 & 50.51 & 1,073 & 35.66 & 5,044 & 55.42 & \\
\hline Non-agricultural work & 2,954 & 24.39 & 1,005 & 33.40 & 1,949 & 21.41 & \\
\hline \multicolumn{8}{|l|}{ Self-report } \\
\hline Good & 1,872 & 16.13 & 492 & 17.13 & 1,380 & 15.81 & 0.000 \\
\hline Fair & 6,142 & 52.93 & 1,615 & 56.23 & 4,527 & 51.85 & \\
\hline Poor & 3,589 & 30.93 & 765 & 26.64 & 2,824 & 32.34 & \\
\hline \multicolumn{8}{|l|}{ Chronic disease type } \\
\hline No chronic disease & 3,020 & 30.14 & 778 & 31.00 & $\overline{2,242}$ & 29.85 & 0.000 \\
\hline Diabetes & 1,433 & 14.30 & 348 & 13.86 & 1,085 & 14.45 & \\
\hline Hypertension & 1,695 & 16.92 & 458 & 18.25 & 1,237 & 16.47 & \\
\hline Diabetes \& Hypertension & 593 & 5.92 & 178 & 7.09 & 415 & 5.53 & \\
\hline Other & 3,279 & 32.72 & 748 & 29.80 & 2,531 & 33.70 & \\
\hline \multicolumn{8}{|l|}{ BMI } \\
\hline Underweight $(<18.5)$ & 639 & 5.25 & 129 & 4.25 & 510 & 5.59 & 0.000 \\
\hline Healthy (18.5-25) & 5,888 & 48.41 & 1,316 & 43.36 & 4,572 & 50.08 & \\
\hline Overweight (25-30) & 2,828 & 23.25 & 794 & 26.16 & 2,034 & 22.28 & \\
\hline Obese $(>30)$ & 2,809 & 23.09 & 796 & 26.23 & 2,013 & 22.05 & \\
\hline
\end{tabular}

*Numbers across the subgroups of some certain characteristics do not add up to the total because of missing values

Table 2: Utilization and expenditure of inpatient care 


\begin{tabular}{|l|l|l|l|l|l|l|l|}
\hline & Overall & & Urban & & Rural & & \\
\hline Healthcare utilization & Mean & SD & Mean & SD & Mean & SD & P \\
\hline $\begin{array}{l}\text { Conditional times of healthcare } \\
\text { visit }\end{array}$ & 1.45 & 0.02 & 1.39 & 0.04 & 1.47 & 0.03 & 0.131 \\
\hline Hospital type & Count & $\%$ & Count & $\%$ & Count & $\%$ & P \\
\hline Not basic health facilities & 1039.0 & 78.42 & 280.0 & 82.84 & 759.0 & 76.9 & 0.022 \\
\hline Basic health facilities & 286.0 & 21.58 & 58.0 & 17.16 & 228.0 & 23.1 & \\
\hline Healthcare expenditure healthcare visit & Mean & SD & Mean & SD & Mean & SD & P \\
\hline $\begin{array}{l}\text { Total } \\
\text { expenditure }\end{array}$ & 6321.00 & 267.47 & 6788.98 & 589.06 & 6163.92 & 297.56 & 0.470 \\
\hline Healthcare visit OOP & 4212.04 & 301.93 & 4457.66 & 389.49 & 4127.83 & 382.89 & 0.000 \\
\hline Health visit reimbursement & 4591.63 & 303.17 & 6087.47 & 708.59 & 4170.30 & 331.70 & 0.001 \\
\hline Total drug expenditure & 2921.16 & 221.24 & 3907.30 & 560.45 & 2649.67 & 235.10 & 0.003 \\
\hline Drug OOP OP & 1924.49 & 190.52 & 2466.93 & 445.12 & 1774.55 & 209.50 & 0.018 \\
\hline Drug reimbursement & Mean & SD & Mean & SD & Mean & SD & P \\
\hline Expenditure\% & $38.6 \%$ & 0.01 & $41.7 \%$ & 0.01 & $37.5 \%$ & 0.01 & 0.015 \\
\hline $\begin{array}{l}\text { Healthcare visit reimbursement } \\
\text { rate }\end{array}$ & $32.4 \%$ & 0.01 & $33.6 \%$ & 0.03 & $32.1 \%$ & 0.02 & 0.452 \\
\hline Drug reimbursement rate & & & & & & & \\
\hline
\end{tabular}

Table 3: Utilization and expenditure of outpatient care last month

\begin{tabular}{|l|l|l|l|l|l|l|l|}
\hline & Overall & & Urban & & Rural & & \\
\hline Healthcare utilization & Mean & SD & Mean & SD & Mean & SD & P \\
\hline Conditional times of healthcare visit & 2.23 & 0.05 & 2.15 & 0.10 & 2.26 & 0.06 & 0.225 \\
\hline Hospital type & Count & $\%$ & Count & $\%$ & Count & $\%$ & P \\
\hline Not basic health facilities & 630 & 27.77 & 163 & 29.69 & 467 & 27.15 & 0.251 \\
\hline Basic health facilities & 1,639 & 72.23 & 386 & 70.31 & 1,253 & 72.85 & \\
\hline Healthcare expenditure & Mean & SD & Mean & SD & Mean & SD & P \\
\hline Total healthcare visit expenditure & 926.56 & 46.83 & 997.79 & 107.65 & 904.21 & 51.42 & 0.897 \\
\hline Healthcare visit OOP & 710.69 & 34.72 & 709.80 & 67.20 & 710.98 & 40.48 & 0.608 \\
\hline Healthcare visit reimbursement & 332.97 & 38.41 & 296.03 & 53.47 & 344.51 & 47.57 & 0.808 \\
\hline Total drug expenditure & 549.53 & 35.60 & 468.67 & 54.23 & 575.47 & 43.67 & 0.464 \\
\hline Drug OOP & 504.56 & 30.26 & 448.68 & 48.17 & 522.95 & 36.96 & 0.645 \\
\hline Drug reimbursement & 110.89 & 17.75 & 99.25 & 42.71 & 114.60 & 19.05 & 0.594 \\
\hline Expenditure\% & Mean & SD & Mean & SD & Mean & SD & P \\
\hline Healthcare visit reimbursement rate & $13.2 \%$ & 0.01 & $13.8 \%$ & 0.01 & $13.1 \%$ & 0.01 & 0.677 \\
\hline Drug reimbursement rate & $9.8 \%$ & 0.01 & $9.2 \%$ & 0.01 & $10.0 \%$ & 0.01 & 0.527 \\
\hline
\end{tabular}

Table 4: Regression results of inpatient care 


\begin{tabular}{|l|l|l|l|l|l|l|}
\hline & Odds ratio & Std. Err. & $\mathbf{z}$ & $\mathbf{P}>\mathbf{z}$ & \multicolumn{2}{l}{$[95 \%$ Conf. Interval] } \\
\hline Living area (urban=ref.) & & & & & & \\
\hline Rural & 1.013 & 0.099 & 0.140 & 0.892 & 0.837 & 1.227 \\
\hline Age (45-=ref.) & & & & & & \\
\hline $45-54$ & 1.225 & 0.318 & 0.780 & 0.434 & 0.737 & 2.038 \\
\hline $55-64$ & 1.362 & 0.355 & 1.190 & 0.236 & 0.817 & 2.269 \\
\hline $65+$ & 1.720 & 0.453 & 2.060 & 0.039 & 1.027 & 2.882 \\
\hline Gender (male=ref.) & & & & & & \\
\hline Female & 0.859 & 0.079 & -1.650 & 0.098 & 0.718 & 1.029 \\
\hline Educational level (no formal=ref.) & & & & & & \\
\hline <=Elementary school & 0.835 & 0.084 & -1.800 & 0.072 & 0.686 & 1.016 \\
\hline$>=$ Middle school & 0.801 & 0.101 & -1.760 & 0.078 & 0.626 & 1.025 \\
\hline Marital status (with spouse=ref.) & & & & & & \\
\hline Living without spouse & 1.165 & 0.123 & 1.440 & 0.149 & 0.947 & 1.433 \\
\hline Work status (unemployment=ref.) & & & & & & \\
\hline Agricultural work & 0.689 & 0.067 & -3.820 & 0.000 & 0.569 & 0.834 \\
\hline Non-agricultural work & 0.607 & 0.082 & -3.710 & 0.000 & 0.466 & 0.790 \\
\hline Self-report (good=ref.) & & & & & & \\
\hline Fair & 1.599 & 0.256 & 2.940 & 0.003 & 1.169 & 2.188 \\
\hline Poor & 4.811 & 0.779 & 9.700 & 0.000 & 3.503 & 6.608 \\
\hline Chronic disease type[no chronic=ref.0 & & & & & & \\
\hline Diabetes & 2.030 & 0.311 & 4.620 & 0.000 & 1.504 & 2.741 \\
\hline Hypertension & 1.780 & 0.266 & 3.870 & 0.000 & 1.329 & 2.385 \\
\hline Diabetes \& Hypertension & 2.480 & 0.445 & 5.060 & 0.000 & 1.744 & 3.527 \\
\hline Other & 1.965 & 0.261 & 5.090 & 0.000 & 1.515 & 2.549 \\
\hline BMI (underweight=ref.) & & & & & & \\
\hline Healthy (18.5-25) & 0.854 & 0.150 & -0.900 & 0.370 & 0.605 & 1.206 \\
\hline Overweight (25-30) & 0.997 & 0.186 & -0.020 & 0.987 & 0.692 & 1.438 \\
\hline Obese (>30) & 1.049 & 0.201 & 0.250 & 0.803 & 0.720 & 1.528 \\
\hline Ln (PCE) & 1.495 & 0.072 & 8.370 & 0.000 & 1.361 & 1.642 \\
\hline $\mathbf{N}$ & 6,464 & & & & & \\
\hline Pseudo R2 & 0.114 & & & & & \\
\hline Prob > chi2 & 0.000 & & & & & \\
\hline
\end{tabular}

Table 5: Regression results of outpatient care 


\begin{tabular}{|l|l|l|l|l|l|l|}
\hline & Odds ratio & Std. Err. & $\mathbf{z}$ & \multicolumn{2}{l|}{$\mathbf{P}>\mathbf{z}$} & \multicolumn{2}{l|}{$[95 \%$ Conf. Interval] } \\
\hline Living area (urban=ref.) & & & & & & \\
\hline Rural & 1.074 & 0.088 & 0.870 & 0.384 & 0.915 & 1.261 \\
\hline Age (45-=ref.) & & & & & & \\
\hline $45-54$ & 1.093 & 0.197 & 0.500 & 0.620 & 0.769 & 1.555 \\
\hline $55-64$ & 0.946 & 0.173 & -0.300 & 0.764 & 0.661 & 1.356 \\
\hline $65+$ & 1.091 & 0.205 & 0.460 & 0.645 & 0.755 & 1.576 \\
\hline Gender (male=ref.) & & & & & & \\
\hline Female & 1.388 & 0.106 & 4.300 & 0.000 & 1.195 & 1.611 \\
\hline Educational level (no formal=ref.) & & & & & & \\
\hline <=Elementary school & 1.014 & 0.087 & 0.160 & 0.875 & 0.857 & 1.199 \\
\hline$>=$ Middle school & 1.145 & 0.119 & 1.300 & 0.194 & 0.934 & 1.404 \\
\hline Marital status (with spouse=ref.) & & & & & & \\
\hline Living without spouse & 0.937 & 0.088 & -0.700 & 0.487 & 0.780 & 1.126 \\
\hline Work status (unemployment=ref.) & & & & & & \\
\hline Agricultural work & 2.465 & 0.327 & 6.810 & 0.000 & 1.901 & 3.195 \\
\hline Non-agricultural work & 5.185 & 0.720 & 11.850 & 0.000 & 3.950 & 6.807 \\
\hline Self-report (good=ref.) & & & & & & \\
\hline Fair & 1.071 & 0.094 & 0.780 & 0.437 & 0.901 & 1.272 \\
\hline Poor & 1.100 & 0.123 & 0.850 & 0.396 & 0.883 & 1.370 \\
\hline Chronic disease type[no chronic=ref.0 & & & & & & \\
\hline Diabetes & 1.699 & 0.205 & 4.390 & 0.000 & 1.341 & 2.152 \\
\hline Hypertension & 1.493 & 0.174 & 3.450 & 0.001 & 1.189 & 1.876 \\
\hline Diabetes \& Hypertension & 1.671 & 0.261 & 3.280 & 0.001 & 1.230 & 2.271 \\
\hline Other & 1.680 & 0.167 & 5.210 & 0.000 & 1.382 & 2.042 \\
\hline BMI (underweight=ref.) & & & & & & \\
\hline Healthy (18.5-25) & 0.779 & 0.115 & -1.700 & 0.090 & 0.583 & 1.040 \\
\hline Overweight (25-30) & 0.731 & 0.115 & -1.980 & 0.047 & 0.537 & 0.996 \\
\hline Obese (>30) & 0.786 & 0.127 & -1.480 & 0.138 & 0.572 & 1.080 \\
\hline Ln (PCE) & 1.071 & 0.042 & 1.750 & 0.081 & 0.992 & 1.157 \\
\hline $\mathbf{N}$ & 6,388 & & & & & \\
\hline Pseudo R2 & 0.063 & & & & & \\
\hline Prob > chi2 & 1.074 & 0.088 & 0.870 & 0.384 & 0.915 & 1.261 \\
\hline
\end{tabular}

\section{Appendix}

\section{Additional file 1: Definition of variables included in model}




\begin{tabular}{|c|c|}
\hline Variables & Definition \\
\hline \multicolumn{2}{|l|}{$\begin{array}{l}\text { Dependent } \\
\text { variables }\end{array}$} \\
\hline $\begin{array}{l}\text { Whether } \\
\text { having an } \\
\text { inpatient } \\
\text { care }\end{array}$ & Having an inpatient care was coded as 1 , not having was coded as 0 \\
\hline $\begin{array}{l}\text { Whether } \\
\text { having an } \\
\text { outpatient } \\
\text { care }\end{array}$ & Having an outpatient care was coded as 1 , not having was coded as 0 \\
\hline \multicolumn{2}{|l|}{$\begin{array}{l}\text { Independent } \\
\text { variables }\end{array}$} \\
\hline Living area & $\begin{array}{l}\text { A dichotomous variable indicates where the respondent lives (urban area is coded as } 0 \text {, } \\
\text { and rural area is coded as } 1 \text { ). }\end{array}$ \\
\hline Age & A categorical variable with 4 levels: $45-, 45-54,55-64$, and $65+$ \\
\hline Gender & $\begin{array}{l}\text { Male and female have different attitudes and needs for health-care services. Male was } \\
\text { coded as } 0 \text {, and female was coded was } 1 \text {. }\end{array}$ \\
\hline Education & $\begin{array}{l}\text { The highest education level attained by the respondent. Education is defined into } 3 \\
\text { dummy variables (no formal education, }<=\text { elementary school, }>=\text { middle school). }\end{array}$ \\
\hline $\begin{array}{l}\text { Living with a } \\
\text { spouse }\end{array}$ & A dichotomous variable indicates whether the respondent lives with a spouse. \\
\hline Work status & $\begin{array}{l}\text { We strata defined observations' work status into three categories: no employment, } \\
\text { agriculture work, and non-agricultural jobs. }\end{array}$ \\
\hline $\begin{array}{l}\text { Self-report } \\
\text { of health }\end{array}$ & $\begin{array}{l}\text { CHARLS has two scales for respondents to self-report their current health condition. } \\
\text { One of the scales ranges from } 1 \text { for Excellent to } 5 \text { for Poor. The other scale ranges from } \\
1 \text { for Very Good to } 5 \text { for Very Bad. Respondents were asked their health status twice, } \\
\text { once in the beginning of the health module and again in the end of the health module. } \\
\text { We recoded these health scales into three categories: good, air, and poor. Good self- } \\
\text { report health status combines respondents who report excellent, very good and good. } \\
\text { Fair self-report health status is consistent with respondents who report fair. Poor self- } \\
\text { report health status combines respondents who report very poor. The reference group } \\
\text { is good health status. }\end{array}$ \\
\hline $\begin{array}{l}\text { Chronic } \\
\text { disease type }\end{array}$ & $\begin{array}{l}\text { Chronic diseases were classified into five categories: no chronic disease, only diabetes, } \\
\text { only hypertension, diabetes and hypertension, and other chronic diseases. Diabetes and } \\
\text { hypertension were defined by biomarkers, while other disease and no chronic disease } \\
\text { were mainly relied on respondents' self-report. }\end{array}$ \\
\hline BMI & $\begin{array}{l}\text { We strata defined BMI into four categories: Underweight }(<18.5) \text {, Healthy (18.5-25), } \\
\text { Overweight }(25-30) \text {, and Obese }(>30) \text {. }\end{array}$ \\
\hline $\begin{array}{l}\text { Total } \\
\text { annually } \\
\text { household } \\
\text { expenditure } \\
\text { per capita } \\
\text { (PCE) }\end{array}$ & $\begin{array}{l}\text { PCE was calculated through dividing total household expenditure by the number of } \\
\text { members in the household }\end{array}$ \\
\hline
\end{tabular}


Additional file 2: Definition of variables used to compare healthcare utilization and expenditures

\begin{tabular}{|c|c|}
\hline Variables & Definition \\
\hline \multicolumn{2}{|l|}{ Healthcare utilization } \\
\hline $\begin{array}{l}\text { Conditional times of } \\
\text { healthcare visit }\end{array}$ & The number of health care visits when respondents have at least one visit. \\
\hline Hospital type & $\begin{array}{l}\text { We strata defined hospital types into two categories: no basic health facilities } \\
\text { and basic health facilities. }\end{array}$ \\
\hline \multicolumn{2}{|c|}{ Healthcare expenditure } \\
\hline $\begin{array}{l}\text { Total healthcare } \\
\text { visit expenditure }\end{array}$ & The total inpatient/outpatient expenditures last year/month \\
\hline $\begin{array}{l}\text { Healthcare visit } \\
\text { OOP }\end{array}$ & The inpatient/outpatient out-of-pocket expenditures last year/last month \\
\hline $\begin{array}{l}\text { Healthcare visit } \\
\text { reimbursement }\end{array}$ & The total healthcare visit reimbursement expenditure \\
\hline $\begin{array}{ll}\text { Total } & \text { drug } \\
\text { expenditure } & \end{array}$ & The total inpatient/outpatient drug expenditure last year/last month \\
\hline Drug OOP & $\begin{array}{l}\text { The total inpatient/outpatient out-of-pocket drug expenditure last year/last } \\
\text { month }\end{array}$ \\
\hline $\begin{array}{l}\text { Drug } \\
\text { reimbursement }\end{array}$ & The total reimbursement drug expenditure. \\
\hline \multicolumn{2}{|l|}{ Expenditure\% } \\
\hline $\begin{array}{l}\text { Healthcare visit } \\
\text { reimbursement rate }\end{array}$ & $\begin{array}{l}\text { The proportion that inpatient/outpatient visit out-of-pocket expenditure } \\
\text { accounts for total healthcare visit expenditure last year/last month }\end{array}$ \\
\hline $\begin{array}{l}\text { Drug } \\
\text { reimbursement rate }\end{array}$ & $\begin{array}{l}\text { The proportion that inpatient/outpatient out-of-pocket drug expenditure } \\
\text { accounts for total drug expenditure last year/last month }\end{array}$ \\
\hline
\end{tabular}

(Especially, all the measures of outpatient care were calculated during last month, and that of inpatient care were calculated during last year. Moreover, total and OOP expenditure of outpatient care only include fees paid for doctor services not for drugs. Total and OOP expenditure of inpatient care only include fees paid for hospital services not for drugs.)

\section{Figures}




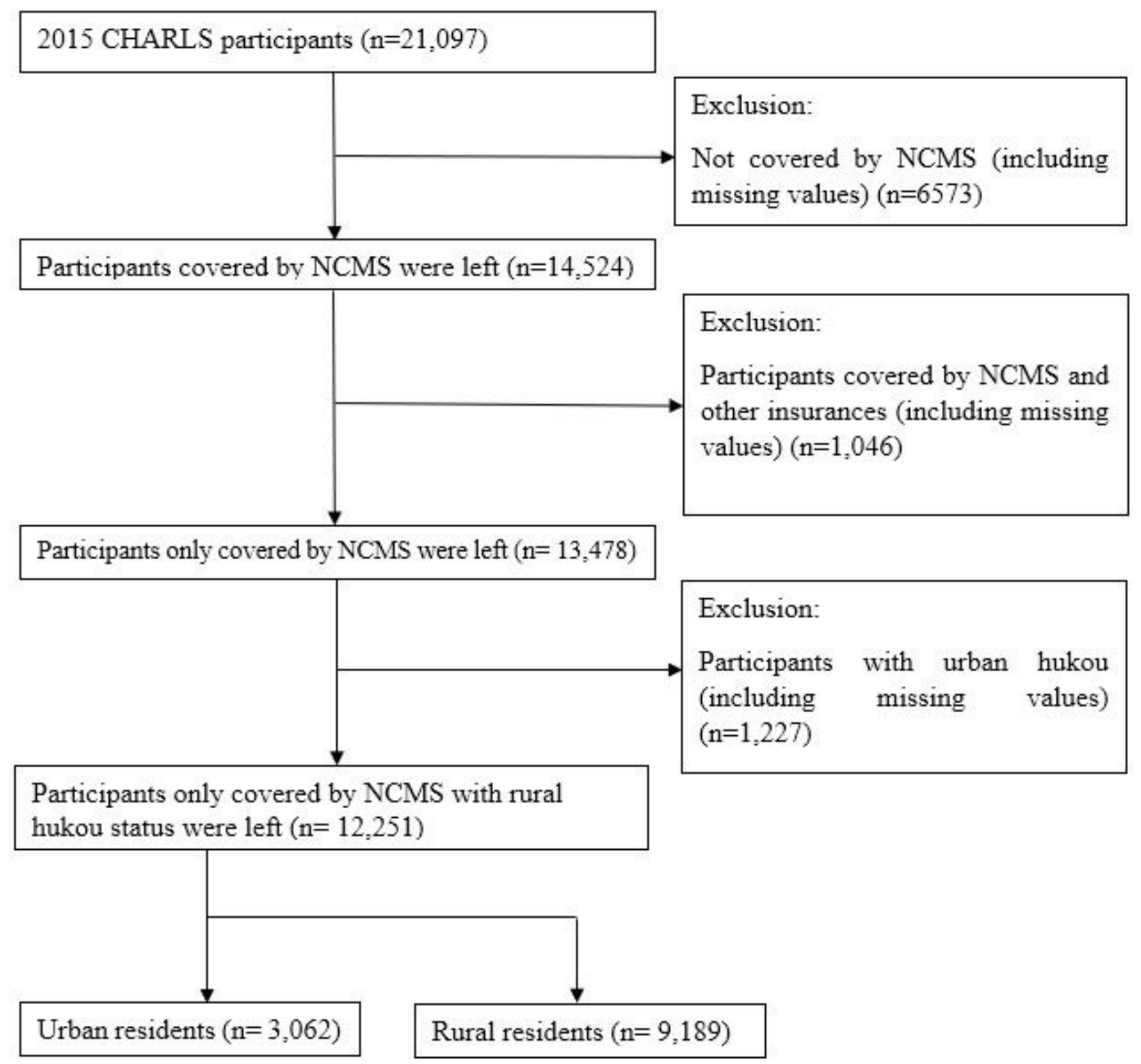

Figure 1

flow chart 